hours, until the disease is completely removed. When the attack threatens to be more severe, the dose is increased to twenty-five, and persevered in night and day, however high the fever and delirium. The only local applications I ever find necessary, are hair powder and cotton wadding. While I depend for the removal of the disease on the iron, it is necessary to attend to the state of the bowels throughout the treatment."

Now I will not take up your valuable space by noting cases individually, but I have used it in erysipelas of the lip, chin, face, and forehead, dependent on carbuncle-in cases of idiopathic and traumatic erysipelas; also, that form induced by dental irritation in the faces of infants. I have also proof of its therapeutic powers even the climate of St. Petersburgh, where a relation of mine, (to whom I had given some, with instructions to take immediately on its appearance) shook off an attack in a week. I had attended him during his first attack in England, and before I used the remedy he was ill one month.

Having suffered the attack before, he was enabled to meet it with timely aid, and communicated the result to me with pleasure. I therefore give my opinion to your numerous readers, and feel sure that a trial will amply compensate them for their experiment. I am satisfied that the suffering from carbuncle, and the carbuncular eruption which has been so prevalent lately, would be much mitigated by a judicious employment of this remedv. I trust I may induce those who have not, to try it, and that I shall escape the censure of those who "knew it before."

Twickenham, November, 1852.

\section{PROLONGED LIFE FROM FOOD ARTIFICIALLY INTRODUCED INTO THE STOMACH.}

By F. W. CASSON, Esq., Hull.

I AM not aware that any case is on record, in which life has been so long sustained by food artificially introduced into the stomach, as the following :-

Miss $\mathrm{H}-$, single, aged forty-five years, of very spare habit and melancholy temperament, was committed to my care in 1844, labouring under religious melancholia. During five years and a half residence in my asylum, her appetite varied considerably; for days successively, she refused to take anything but biscuits and water, at other times she ate great quantities of food, and especially beef, with a large proportion of fat. From the 22nd of August, 1848, to the 12th of February, 1849, she positively refused everything, even water, during which period, she was fed by the stomach-pump on beef-tea, eggs, gruel, \&c. \&c. On the 13th of February, she sipped some cold water, and from this date, until the 16th of March, continued to do so at intervals, on the latter day taking treacle and water. She occasionally drank water, or treacle and water, up to the 28th of of April, obstinately refusing from this period until her death, (which occurred January 4th, 1850, all food, \&c., except that which was given by the stomach-pump. For sixteen months, then, this lady had the pump introduced daily-sometimes moistening the passages with fluid, but life was wholly sustained during rather more than eight months by the artificial introduction of everything that entered the stomach.

The only reason that my patient ever assigned for abstaining from food, was, that she feared to produce pain in her mouth, to which she had been subject; I believe, however, that she had some religious scruples, which I could never induce her to disclose.

It was somewhat singular to witness (after the first three or four introductions of the tube) the eagerness with which she assisted in the operation, and the great anxiety manifested lest I should forget her times of taking food.

November, 1852.

Health of London during the WeEK ending Saturday, November 27.-The weekly return continues to exhibit a comparatively favourable condition of the public health. In the week that ended last Saturday the deaths were 947, a number which differs not much from that of the preceding week. In the ten corresponding weeks of the years $1842-51$ the average number was 1087 , which, if a correction is made for increase of population, gives a mortality for the present time of 1196. Compared with this estimated amount, the deaths actually returned last week show a reduction of 249 . Last week the deaths from scarlatina again rose from 59 to 72 , those from typhus fell from 50 to 37 . There were 7 deaths from small-pox, and 15 from measles. Diseases of the respiratory organs are at nearly the same amount as in the preceding week.

\author{
A fentror \\ OF THE PRACTICE OF
MEDICINE AND SURGERY
IN THE
HOSPITALS OF LONDON.

Nulla est alia pro certo noscendi via, nisi quam plurimas et norborum, et dissectionum historias, tum aliorum proprias, collectas habere et inter se comparare.-Morgagni. De Sed. et Cuus. Morb., lib.14. Procmium.

\section{CASES OF EXCISION OF JOINTS.}

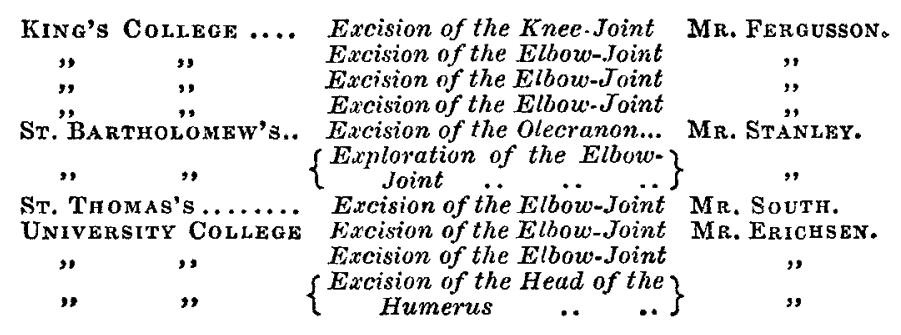

\section{KING'S COLLEGE HOSPITAL.}

Excision of the Knee-joint.

(Under the care of Mr. Feraussox.)

Amputatron of the arm for disease of the elbow or shoulderjoint is in these days but seldom performed; and there is an unmistakable tendency among our hospital surgeons, in cases of chronic articular affections, to save the limb by removing the diseased portions of bone which enter into the formation of the joint. This anxiety for preserving useful limbs certainly forms a very great contrast with the recklessness with which they formerly used to be removed, and we are glad to say, that in many instances which have come under our cognizance, very good semi-anchylosed arms have been preserved.

Still, it should always be borne in mind that the process of cicatrization is in these cases very long, and that no results should in general be expected before a twelvemonth has elapsed. When surgeons and their patients are fully aware of this circumstance, they save themselves a vast deal of dis. appointment. But hardly any fault can be found with the length of this period, for we have often to wait much longer for a little improvement in the joint, when no decisive measures are adopted; so that the patient cannot be a great loser, except as regards the early effects of the operation. Now these effects have never, or seldom, been found of a dangerous kind, where the elbow, shoulder, ankle or foot, were concerned, and numerous cases are on record which prove that in but very few, immediate mischief occurred. But this remark does not hold good as regards the knee-joint; the excision of this articulation is fraught with danger, and should be undertaken only after very mature consideration, and a careful calculation of the other chances which may be held out by a different course of proceeding.

There will always be this great difference between the upper and lower extremity, as regards excision, that the latter has to bear the weight of the body, and to be used for progression. And with respect to the knee-joint in particular, there is an additional circumstance of importance- viz., the great size of the articulation, the large amount of bone which is removed, and the extent of the wound necessary for excision.

At the ankle or foot, though even one or two bones of the tarsus or metatarsus may be taken away, a sufficient system of osseous textures is left to combine, consolidate, and answer, though imperfectly, many of the purposes of the limb. But with the knee the shortening must be considerable, the formation of a false joint can hardly be expected, and the most favourable termination seems to be complete and bony anchylosis. An anchylosed leg is, however, far preferable to none at all, and the operation wonld in that respect be justifiable, provided statisties would sufficiently show that the 
danger accompanying the operation is not of too palpable a kind.

We shall not at present dwell on numerical considerations; these have been set forth in a late number of this journal, (THE LANCET, vol. ii. 1852 , p. 426,) and we merely beg to remark, that much in this operation must depend on the patient's state of health, the manner in which the excision is performed, and the more or less attention paid to the after-treatment. We are glad to find that, in the present case, all these requisites are in favour of the patient; she has done hitherto remarkably well, the immediate danger of life is passed, and it is very likely that she will recover. Time will slow, however, (and we shall carefully take note of the facts, ) to what extent the girl will be able to make use of the limb.

Mr. Fergusson has of late performed excision of joints several times; he has been particularly successful in the resection of the elbow, and we beg to offer this week to our readers a connected account, not only of the operations per formed by Mr. Fergusson, but also of those which have taken place in other hospitals. The table placed above will show at one glance that our present reports, except Mr. Fergusson's excision of the knee-joint, are confined to operations performed on the upper extremity.

The following particulars are obtained from the notes of Mr. Macaulay, one of Mr. Fergusson's dressers:-

Anne $\mathrm{G}-$, aged twenty years, and unmarried, was admitted into Adelaide ward, April 20, 1852. The patient has lived for the last two years in Iondon as a servant-maid, and used to kneel a great deal. Six months before admission, without any blow or injury, the left knee became slightly swollen and painful, especially during the night. The swelling continued to increase, and the girl remained an out-patient for two months at Charing-cross Hospital, without deriving any benefit from the treatment. On her admission into King's College Hospital, the knee was found a little flexed, swollen, and painful; the leg was at once placed on a straight splint, and poultices applied.

Five weeks after admission the pain and tumefaction had increased, and thereupon two issues were made on each side of the joint. Nine days afterwards the pain was very acute, and the swelling considerable, though no reduess was noticed. Thirteen days now passed, and the swelling had not diminished; a large issue was therefore placed over the patella, the least motion of the limb causing agonizing pain. A few days afterwards the pain was much relieved by the limb being placed into Salter's swinging apparatus.

Four months after admission, Mr. Fergusson made a puncture into the joint, and gave exit to half an ounce of serous, turbid fluid. One week after the adoption of this measure, the swelling had not diminished, and the pain on the least motion was extremely severe. Mercury was now tried, and slight salivation induced, but without any impression being made on the state of the joint.

Six months after admission the patient was put under the influence of chloroform, and Mr. Fergusson instituted a thorough examination of the knee. A rough grating was heard when the patella was rubbed against the condyles of the femur, and the lateral motions of the joint were freer than natural. Eleven days after this examination, (October 30 1852,) being six months and a half after admission, $\mathrm{Mr}$. Fergusson proceeded to the excision of the joint.

Chloroform having been administered, Mr. Fergusson made an exploratory puncture into the articulation, by which a considerable quantity of turbid serum was freed. On passing the finger into the joint, the articular surfaces were felt rough, and denuded of their cartilage. Mr. Fergusson now made such incisions as would bring the joint into view, and allow him either to take off the thigh at the lower third, or excise the joint, according to the state in which the parts would be found.

These incisions consisted of two lateral ones carried longitudinally on either side of the joint, and a transverse one, uniting the two lateral cuts, about two inches below the patella. A flap was then raised from the front of the joint in the manner of a lid, the hinge of which was situated about the middle of the lower third of the thigh. The patella was of course attached to this flap, and presented, when the latter was turned up, its posterior or articular surface. The joint exhibited considerable thickening of the synovial membrane, with sero-sanguineous secretion from the ulcerated cartilages. Under these circumstances, Mr. Fergusson resolved to make an attempt at saving the limb, and removing the processes of bone entering into the formation of the joint. The condyles of the femur and the head of the tibia and fibula were sawn off, the instrument cutting very easily through the soft and adipose cancellous structure; the patella was then easily disconnected from the flap in which it was fixed; the projecting masses of thickened synovial membrane were pared, and a few vessels tied.

The haemorrhage was altogether very inconsiderable. Mr. Fergusson now placed the cut extremities of the fernur, tibia, and fibula into apposition; but in doing this, he found that the flap originally made was too long; a portion of it, about one inch and a half in depth, was therefore cut off transversely. The wound was closed with sutures; and large pieces of lint, damp with cold water, secured by a roller, were applied to the joint. The patient was placed in bed, the limb lying on a straight channelled splint with foot-piece, being gently supported by Salter's swing, and so adjusted as to be somewhat raised.

After the operation, Mr. Fergusson said that he had found the joint in as diseased a state as he had anticipated. $\mathrm{He}$ had now availed himself of a great improvement in practice, which was founded upon statistical data. The manner in which the joint had been brought into view, would have al lowed him to perform amputation, if such an operation had been found necessary. Mr. Fergusson hoped this case would prove successful; and he had some reason for the view he was taking, since three out of seven cases on record had terminated. favourably. Mr. Jones, of Jersey, had been fortunate in this operation; but even on general principles, and from what we now knew of excision of joints, the procedure was justifiable. He (Mr. Fergusson), as the pupils could recollect, had had an unsuccessful case of this kind, (The Lancet, vol. ii. 1850, p. 183;) but he thought he had done more for this girl, whose health is still robust, than if he had performed the easier operation-namely, the removal of the limb.

On examining the excised processes of bone, it was found that the articular surfaces of the femur and tibia were bared of cartilage, except in a very small spot, the patella being in the same condition.

Nine o'clock P.M. : The patient has been kept under the influence of opium, and is not in very great pain. A slight oozing of blood. Pulse 146, soft. The girl has been slightly sick.

Second day.-One P.M.: The patient is not in much pain; pulse 176 , weak; tongue white and moist; the bandage was cut through, though the wound was not tense, and no blood was found in it.-Ten o'clock P.M.: Pulse 140; respiration easy; the edges of the wound were being covered with lymph. The patient has again been sick; she takes egg and brandy in teaspoonfuls, to allay the gastric irritability. There has been pain and slight starting of the thigh.

Third day.-Pulse 144; breathing easy; has been slightly sick again; no pain in the thigh or knee; more action in the wound. Continue the egg and brandy.

Fourth day.-This morning the girl is more cheerful; pulse 120 ; she takes some clear soup, which she keeps down. Suppuration has commenced.

Fifth day.-Very comfortable and cheerful; there is not much pain in the knee. She continues the gravy soup and eggs. The dressings and splints were now changed; the skin which covered the patella (being very thin) has slightly ulcerated; thero is a plentiful discharge of pus; the stitches were removed.

Sixth dav.-Rather feverish; she does not fancy her food; the bowels have not been opened since the operation. An enema was given, and came away untinged. In the evening, an ounce of castor-oil was administered, and an evacuation was obtained an hour afterwards.

After this period, the patient went on improving. On the fifteenth day, Mr. Lawson, the house-surgeon, fitted the limb in a box, and slung the whole as before. The bowels became quite regular; and on the twenty-first day, the ends of the bones were in close apposition, and covered with healthy granulations, the external wounds being rapidly advancing towards cicatrization; pulse 104.

Thus far the case has proceeded very favourably; and we trust to be able, on a further occasion, to announce the patient's final recovery.

We now come to a case of unusual interest, for the patient had sought relief in various charitable institutions for the last seven years, and the most appropriate and skilfully combined remedies had been of no avail in restoring the elbowjoint. Excision of the semi-anchylosed and almost consolidated articulation has had complete success, as will be seen by the following details obtained from the notes of Mr. Hulke, one of Mr. Fergusson's dressers:- 